\title{
Colposcopy attendance and deprivation: A retrospective analysis of 27193 women in the NHS Cervical Screening Programme
}

\author{
E Douglas ${ }^{1}$, J Wardle ${ }^{1}$, N J Massat ${ }^{2}$ and J Waller ${ }^{\star}, 1$ \\ ${ }^{1}$ Health Behaviour Research Centre, Department of Epidemiology \& Public Health, University College London, Gower Street, \\ London WC1E 6BT, UK and ${ }^{2}$ Centre for Cancer Prevention, Wolfson Institute of Preventive Medicine, Queen Mary University of \\ London, London, UK
}

Background: Attendance for cervical screening is socially graded, but little is known about patterns of attendance for colposcopy following an abnormal screening result.

Methods: Logistic regression was used to regress colposcopy attendance status for 27193 women against age and area-level deprivation, adjusting for ethnicity.

Results: Colposcopy attendance was high at 8 weeks (89\%) and 4 months post-referral (94\%) but women living in the most deprived areas were significantly less likely to attend.

Conclusions: The high overall attendance rates at colposcopy are encouraging but lower attendance among women in the most income-deprived areas indicates that even when these women attend primary cervical screening, they remain at higher risk of missing out on the benefits of the programme.

Introduction of an organised cervical screening programme in the UK in 1988 dramatically reduced cervical cancer incidence and mortality (Quinn et al, 1999; Peto et al, 2004), and protected the population against rises in incidence that would probably have occurred because of changes in sexual behaviour (Mercer et al, 2013). The cervical screening programme offers 3-5 yearly testing for cytological abnormalities (Health and Social Care Information Centre, 2013), with referral to colposcopy for further investigation and treatment if abnormalities are detected. The success of the programme depends on high attendance at both primary screening and colposcopy.

Screening attendance has consistently been found to be lower in women who live in more deprived areas (Baker and Middleton, 2003; Webb et al, 2004; Bang et al, 2012), have lower levels of education (Sabates and Feinstein, 2006) or lower socioeconomic status (SES) (Moser et al, 2009). Other factors such as younger age (Lancucki et al, 2010; Albrow et al, 2012) and non-white ethnicity (Webb et al, 2004; Moser et al, 2009) are strong predictors of lower attendance although ethnicity may be confounded with SES. Much less is known about patterns of attendance at colposcopy followup. In the TOMBOLA trial, colposcopy attendance was very high (around 93\%) (Sharp et al, 2012). However, attendance was lower in women who were younger and less educated. Late attendance for colposcopy (more than 6 months after the original appointment) was also associated with having less education, and it predicted non-attendance for subsequent colposcopy appointments (Sharp et al, 2012).

We know of no analyses of socioeconomic patterns of attendance at colposcopy using individual-level attendance data from the national screening programme. National appointmentlevel data for England showed attendance of 77\% in 2012-2013; but this underestimates attendance at the individual level, because it fails to account for women who miss or cancel one appointment but attend a second one soon afterwards (Health and Social Care Information Centre, 2013). Appointment-level data may mask demographic patterns of attendance if certain groups are

*Correspondence: Dr J Waller; E-mail: j.waller@ucl.ac.uk

Received 16 January 2015; revised 14 April 2015; accepted 22 April 2015;

published online 21 May 2015

(c) 2015 Cancer Research UK. All rights reserved 0007-0920/15

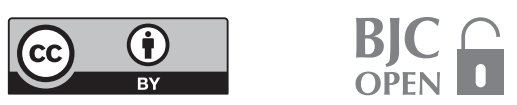


disproportionately likely to rearrange but subsequently attend appointments.

We used patient-level data, which is now available in some areas in England (NHS Cancer Screening Programme, 2011), to explore demographic differences in colposcopy attendance. We hypothesised that patterns of attendance would mirror those in primary screening, with women of lower SES less likely to attend.

\section{MATERIALS AND METHODS}

Data and variables. The source of data was the East of England Cyres Colposcopy database, covering a screening eligible population of $\sim 1.5$ million women (ONS, 2014a). Anonymised data were extracted for all women referred to colposcopy following an abnormal screening result from 2006-2013. Referral date is defined as the date at which cytology is reported. Colposcopy attendance was ascertained by tracking patients from referral to appointment status 8 weeks later, allowing them to re-book their initial appointment within that time period. Women were categorised as 'attenders' or 'non-attenders' at 8 weeks. This time interval was chosen because $98 \%$ of women referred to colposcopy are offered an appointment within 8 weeks (Health and Social Care Information Centre, 2013). A secondary analysis examined attendance at 4 months. This interval was chosen because cervical cancer detected $<4$ months after a screening referral is considered to be 'screen-detected' (NHS Cancer Screening Programme, 2011).

For each individual, data were downloaded on age and Lower Super Output Area (LSOA) for the postcode of their home address at the time of referral. We used LSOA to access local area-level values for deprivation (the income domain of the Index of Multiple Deprivation) (Department for Communities and Local Government, 2011) and ethnic diversity (percentage of the population from white ethnic backgrounds) (ONS, 2014b). The income domain was chosen because it is likely to be relatively homogeneous within LSOAs and so is more likely to reflect individual-level income (ONS, 2007).

Categorical variables were constructed for age (25-34, 35-44 and 45-64 years) and deprivation (quintiles based on national data (Knowledge \& Information Team, Public Health England, 2011)). Ethnic diversity was used as a continuous variable.

The study was exempt from the need for ethical approval under the UCL Ethics Committee guidelines.

Analysis. Multiple logistic regression (Hosmer and Lemeshow, 2004) was used to regress colposcopy attendance status (using 8week and 4-month cut-offs) against age and deprivation, prior to and after adjusting for ethnicity.

\section{RESULTS}

Characteristics of the sample. During 2006-2013, 27193 women were referred for colposcopy. Where an individual woman had more than one colposcopy referral, we only included the first. Women had a mean age of 35 years (standard deviation $=9.1$ ), mostly lived in areas within the upper four quintiles of deprivation, reflecting the relative affluence of the East of England in comparison with the country as a whole, and came from areas of predominantly white ethnicity.

Colposcopy attendance and socio-demographic variables. Overall, $89.3 \%$ of women attended for colposcopy within 8 weeks (Table 1). In unadjusted analyses, women in the lowest quintile of income had significantly lower odds of attendance compared with the highest income quintile $(86.6 \%$ compared with $89.1 \%$, odds ratio $(\mathrm{OR})=0.79,95 \% \mathrm{CI}: 0.68-0.91)$. There was no significant association between age and attendance within 8 weeks. In the model adjusted for area-level ethnic diversity, the OR for the lowest income group was slightly attenuated but remained significant $(\mathrm{OR}=0.83$, 95\% CI: 0.72-0.97)

When we examined attendance within 4 months, mean attendance was $94 \%$ (Table 2). In the unadjusted analysis, women living in the lowest income area were significantly less likely to attend $(92.5 \%$ vs 94.1\%; OR $=0.76,95 \%$ CI: 0.63-0.93). In the adjusted model, women living in the lowest quintile remained significantly less likely to attend, though as before, the association was slightly attenuated after adjustment for area-level ethnicity ( $\mathrm{OR}=0.81,95 \% \mathrm{CI}$ : 0.67-0.98). Women aged 45-64 years were significantly more likely to attend colposcopy in unadjusted $(\mathrm{OR}=1.25,95 \% \mathrm{CI}$ : $1.08-1.45)$ and adjusted models $(\mathrm{OR}=1.23,95 \% \mathrm{CI}$ : $1.06-1.43)$, than women in the 25-34 year reference category.

\section{DISCUSSION}

This is the first study of individual-level colposcopy attendance following an abnormal screening result in the organised cervical screening programme in England. We investigated attendance within 8 weeks, which is the value used in appointment-level statistics, and attendance within 4 months to include late attenders' who may still attend within the time frame in which cervical cancer, if diagnosed, is considered to be 'screen-detected' (NHS Cancer Screening Programme, 2011).

Attendance within 8 weeks of referral was lower than attendance in the multi-centre population-based randomised controlled trial nested in the NHS Cervical Screening Programme (TOMBOLA) (Sharp et al, 2012) (89\% compared with 93\%) but our 4-month

Table 1. Analyses of variables associated with colposcopy attendance within 8 weeks of referral

\begin{tabular}{|c|c|c|c|c|c|c|}
\hline & \multirow[b]{2}{*}{ Sample column \% (n) } & \multirow[b]{2}{*}{8 week attenders row $\%(n)$} & \multicolumn{2}{|c|}{ Unadjusted models } & \multicolumn{2}{|c|}{ Adjusted model ${ }^{a}$} \\
\hline & & & OR $(95 \% \mathrm{Cl})$ & $P$-value & OR $(95 \% \mathrm{Cl})$ & $P$-value \\
\hline & 100 (27 193) & $89.3(24294)$ & & & & \\
\hline \multicolumn{7}{|l|}{ Income quintile } \\
\hline $\begin{array}{l}\text { Q1-Low income } \\
\text { Q2 } \\
\text { Q3 } \\
\text { Q4 } \\
\text { Q5-High income }\end{array}$ & $\begin{array}{c}8.5(2305) \\
22.3(6064) \\
26.7(7255) \\
22.5(6115) \\
20.1(5454)\end{array}$ & $\begin{array}{l}86.6(1996) \\
89.6(5434) \\
89.4(6486) \\
90.2(5517) \\
89.1(4861)\end{array}$ & $\begin{array}{c}0.79(0.68-0.91) \\
1.05(0.94-1.19) \\
1.03(0.92-1.15) \\
1.13(1.00-1.27) \\
1.00\end{array}$ & $\begin{array}{l}0.001^{\star} \\
0.400 \\
0.622 \\
0.053 \\
-\end{array}$ & $\begin{array}{c}0.83(0.72-0.97) \\
1.12(0.99-1.26) \\
1.04(0.93-1.16) \\
1.12(0.99-1.26) \\
1.00\end{array}$ & $\begin{array}{c}0.016^{\star} \\
0.075 \\
0.514 \\
0.075 \\
-\end{array}$ \\
\hline \multicolumn{7}{|l|}{ Age } \\
\hline $\begin{array}{l}25-34 \text { years } \\
35-44 \text { years } \\
45-64 \text { years }\end{array}$ & $\begin{array}{c}55.0(14949) \\
27.7(7539) \\
17.3(4705)\end{array}$ & $\begin{array}{c}89.5(13372) \\
88.8(6691) \\
89.9(4231)\end{array}$ & $\begin{array}{c}1.00 \\
0.93(0.85-1.02) \\
1.05(0.95-1.17)\end{array}$ & $\begin{array}{l}-\overline{111} \\
0.353\end{array}$ & $\begin{array}{c}1.00 \\
0.92(0.84-1.00) \\
1.03(0.92-1.15)\end{array}$ & $\begin{array}{l}-\overline{0} \\
0.053 \\
0.607\end{array}$ \\
\hline
\end{tabular}




\begin{tabular}{|c|c|c|c|c|c|c|}
\hline & \multirow[b]{2}{*}{ Sample column \% (n) } & \multirow[b]{2}{*}{4 month attenders row $\%(n)$} & \multicolumn{2}{|c|}{ Unadjusted models } & \multicolumn{2}{|c|}{ Adjusted model ${ }^{a}$} \\
\hline & & & OR $(95 \% \mathrm{Cl})$ & $P$-value & OR $(95 \% \mathrm{Cl})$ & $P$-value \\
\hline & $100(27$ 193) & $94.1(25594)$ & & & & \\
\hline \multicolumn{7}{|l|}{ Income quintile } \\
\hline Q1-Low income & $8.5(2305)$ & $92.5(2131)$ & $0.76(0.63-0.93)$ & $0.006^{\star}$ & $0.81(0.67-0.98)$ & $0.031^{*}$ \\
\hline Q2 & 22.3 (6064) & 94.5 (5731) & $1.08(0.92-1.26)$ & 0.362 & $1.13(0.97-1.33)$ & 0.122 \\
\hline Q3 & 26.7 (7255) & 94.1 (6828) & $1.00(0.86-1.16)$ & 1.000 & $1.01(0.87-1.18)$ & 0.875 \\
\hline Q4 & 22.5 (6115) & 94.4 (5771) & $1.05(0.89-1.23)$ & 0.549 & $1.04(0.89-1.22)$ & 0.593 \\
\hline Q5-High income & 20.1 (5454) & $94.1(5133)$ & 1.00 & - & 1.00 & - \\
\hline \multicolumn{7}{|l|}{ Age } \\
\hline $25-34$ years & 55.0 (14949) & 93.9 (14038) & 1.00 & - & 1.00 & - \\
\hline $35-44$ years & 27.7 (7539) & 94.0 (7083) & $1.01(0.90-1.13)$ & 0.893 & $1.00(0.89-1.12)$ & 0.941 \\
\hline $45-64$ years & $17.3(4705)$ & $95.1(4473)$ & $1.25(1.08-1.45)$ & $0.003^{*}$ & $1.23(1.06-1.43)$ & $0.006 *$ \\
\hline
\end{tabular}

attendance was similar (94\%). There is a fail-safe process in place in England to manage women who do not attend colposcopy to minimise loss to follow-up. This includes sending reminder letters and informing the GP of non-attendance, but may vary between colposcopy clinics (NHS Cancer Screening Programme, 2010). The higher attendance at 4 months may be in part due to efforts to encourage women to attend over the extended period; efforts that appear to be effective across all quintiles of deprivation.

High levels of attendance ( $88 \%$ ) have also been reported for referral to colonoscopy following a positive faecal occult blood test in the colorectal cancer screening programme (Morris et al, 2012). These findings suggest that once a cancer screening invitation is accepted, compliance with recommended follow-up and treatment is likely to be high. That said, minimising missed appointments, which increase the risk of delayed diagnosis of cervical cancer (NHS Cancer Screening Programme, 2011) and are costly to the NHS (Bech, 2005), remains important despite overall high rates of attendance.

Women from the most income-deprived areas had lower colposcopy attendance at both time points, even after adjusting for area-level ethnicity, but the dose-response association often observed between screening uptake and SES was not seen. This suggests that barriers to colposcopy attendance may be concentrated in the most deprived groups, although this requires further exploration. The association between deprivation and low uptake is consistent with findings from two retrospective studies of colposcopy clinic data in England (Sanders et al, 1992; Orbell et al, 2006). The TOMBOLA study also found that attendance was lower in women with no post-school education (Sharp et al, 2012).

Older women (aged 45-64 years) were significantly more likely to attend colposcopy within 4 months than younger women, consistent with the TOMBOLA study (Sharp et al, 2012). The significant association between age and colposcopy attendance was, however, not found at 8 weeks. This suggests that of the women who have not attended at 8 weeks, older women are more likely to have delayed attendance but attended within 4 months. Analyses of age differences in primary cervical screening attendance suggest that older women are less likely to cite difficulties in either making an appointment or finding time to attend screening, but may have a lower perceived risk of cervical cancer (Waller et al, 2011), which may lead to delayed attendance. 'Late attenders' at first referral to colposcopy have been found to be more likely to not attend subsequent follow-up colposcopy appointments (Sharp et al, 2012), therefore gaining further understanding of this issue is an important avenue for future research.

Explanations for non-attendance at colposcopy include physical (Marteau et al, 1990), psychological (Marteau et al, 1990; Wardle et al, 1995; McCaffery et al, 2006; Gray et al, 2006), educational (Lindau et al, 2006) and practical factors (Orbell et al, 2006;
Balasubramani et al, 2008; Linsell et al, 2010). One study found evidence that history of domestic violence is a strong predictor of colposcopy default and loss to follow-up (Collier and Quinlivan, 2014), but there is limited research on socio-demographic variation in barriers to colposcopy. Further research in this area is warranted.

This study benefited from the use of a very large sample of women from the NHS screening programme. However, using arealevel variables for SES and ethnicity is a potential weakness of the study. Socioeconomic status and ethnicity data are not routinely collected by the cervical screening programme, but we were able to match to LSOA level. Lower Super Output Areas are small, homogenous geographical areas designed for neighbourhood statistical analyses (ONS, 2007). The East of England region has relatively high colposcopy attendance in comparison with other regions (Health and Social Care Information Centre, 2013), but linking the area-level measures to national quintiles may increase the relevance of these results for other regions in England. We were not able to look at mediators of the demographic patterns observed, and future work might usefully investigate the relationship between deprivation and other factors such as practical barriers and psychological well-being.

\section{CONCLUSION}

The high attendance rate at colposcopy is encouraging because it indicates that, in this area of England at least, women who accept an invitation to cervical screening are likely to accept a referral to colposcopy. However, lower attendance among women in the most income-deprived areas is of concern because this suggests that even when they attend cervical screening, they are at increased risk of missing out on the benefits of the programme. There is a need for research designed to understand the mechanisms through which deprivation is linked to lower colposcopy attendance to inform future intervention development.

\section{ACKNOWLEDGEMENTS}

With thanks to Jullien Brady (Quality Assurance Director for the East of England Region), Simon Wrathall (East of England Screening QARC) and Graham Phillips (Public Health England) for their support in sourcing and understanding the colposcopy data downloaded from the East of England region. With thanks to Alex Castenon (Wolfson Institute of Preventive Medicine, Queen Mary University of London) for feedback on earlier versions of the 
paper. This study is funded by a grant from the UK Department of Health (no. 106/0001). ED and NM are supported by the Policy Research Unit in Cancer Awareness, Screening, and Early Diagnosis. The Policy Research Unit receives funding for a research programme from the Department of Health Policy Research Programme. It is a collaboration between researchers from seven institutions (Queen Mary University of London, University College London, King's College London, London School of Hygiene and Tropical Medicine, Hull York Medical School, Durham University and Peninsula Medical School). The views expressed are those of the authors and not necessarily those of the NHS, or the Department of Health. JW and JoW are supported by Cancer Research UK.

\section{CONFLICT OF INTEREST}

The authors declare no conflict of interest.

\section{REFERENCES}

Albrow R, Kitchener H, Gupta N, Desai M (2012) Cervical screening in England: The past, present, and future. Cancer Cytopathol 120: 87-96.

Baker D, Middleton E (2003) Cervical screening and health inequality in England in the 1990s. J Epidemiol Community Health 57: 417-423.

Balasubramani L, Orbell S, Hagger M, Brown V, Tidy J (2008) Can default rates in colposcopy really be reduced? BJOG 115: 403-408.

Bang JY, Yadegarfar G, Soljak M, Majeed A (2012) Primary care factors associated with cervical screening coverage in England. J Public Health 34: 532-538 at http://jpubhealth.oxfordjournals.org/content/34/4/532.

Bech M (2005) The economics of non-attendance and the expected effect of charging a fine on non-attendees. Health Policy 74: 181-191.

Collier R, Quinlivan JA (2014) Domestic violence is a leading risk factor in default from colposcopy services. J Obstet Gynaecol Res 40: 1785-1790.

Department for Communities and Local Government (2011) The English Indices of Deprivation 2010. 1-145 at http://www.communities.gov.uk/ documents/statistics/pdf/1870718.pdf.

Gray NM, Sharp L, Cotton SC, Masson LF, Little J, Walker LG, Avis M, Philips Z, Russell I, Whynes D, Cruickshank M, Woolley CM. TOMBOLA group (2006) Psychological effects of a low-grade abnormal cervical smear test result: anxiety and associated factors. Br J Cancer 94: 1253-1262.

Health and Social Care Information Centre (2013) Cervical Screening Programme, England 2012-13.

Hosmer DW, Lemeshow S (2004) Applied Logistic Regression. John Wiley \& Sons: New York, NY, USA.

Knowledge \& Information Team, Public Health England (2011) English Indices of Deprivation 2010-adjustments to align Income Domain scores with 2011 boundaries for Lower Layer Super Output Areas (LSOAs) at https://www.gov.uk/government/publications/english-indices-ofdeprivation-2010.

Lancucki L, Fender M, Koukari A, Lynge E, Mai V, Mancini E, Onysko J, Ronco G, Tornberg S, Vessey M, Patnick J (2010) A fall-off in cervical screening coverage of younger women in developed countries. J Med Screen 17: 91-96.

Lindau ST, Basu A, Leitsch SA (2006) Health literacy as a predictor of follow-up after an abnormal pap smear: a prospective study. J Gen Intern Med 21: 829-834.

Linsell L, Forbes LJ, Patnick J, Wardle J, Austoker J, Ramirez AJ (2010) Women's preferences for the delivery of the National Health Service Breast Screening Programme: a cross-sectional survey. J Med Screen 17: 176-180.

Marteau TM, Walker P, Giles J, Smail M (1990) Anxieties in women undergoing colposcopy. BJOG 97: 859-861.

McCaffery K, Waller J, Nazroo J, Wardle J (2006) Social and psychological impact of HPV testing in cervical screening: a qualitative study. Sex Transm Infect 82: 169-174.
Mercer CH, Tanton C, Prah P, Erens B, Sonnenberg P, Clifton S, Macdowall W, Lewis R, Field N, Datta J, Copas AJ, Phelps A, Wellings K, Johnson AM (2013) Changes in sexual attitudes and lifestyles in Britain through the life course and over time: findings from the National Surveys of Sexual Attitudes and Lifestyles (Natsal). Lancet 382: 1781-1794.

Morris S, Baio G, Kendall E, von Wagner C, Wardle J, Atkin W, Halloran SP, Handley G, Logan RF, Obichere A, Rainbow S, Smith S, Snowball J, Raine R (2012) Socioeconomic variation in uptake of colonoscopy following a positive faecal occult blood test result: a retrospective analysis of the NHS Bowel Cancer Screening Programme. Br J Cancer 107: 765-771.

Moser K, Patnick J, Beral V (2009) Inequalities in reported use of breast and cervical screening in Great Britain: analysis of cross sectional survey data. BMJ 338: b2025.

NHS Cancer Screening Programme (2010) Colposcopy and Programme Management-nhscsp20.pdf. at http://www.cancerscreening.nhs.uk/ cervical/publications/nhscsp20.pdf.

NHS Cancer Screening Programme (2011) NHSCSP Audit of invasive cervical cancer at http://www.cancerscreening.nhs.uk/cervical/publications/nhscspaudit-invasive-cervical-cancer-201107.html.

ONS (2007) Neighbourhood Statistics: Super Output Areas Explained at http://www.neighbourhood.statistics.gov.uk/dissemination/ Info.do? $m=0 \& s=1404374781038 \&$ enc $=1$ \&page $=$ nessgeography $/$ superoutputareasexplained/output-areas-explained.htm\&nsjs= true\&nsck=false\&nssvg=false\&nswid $=1366$.

ONS (2014a) Population Estimates for UK, England and Wales, Scotland and Northern Ireland, Mid 2013 at http://www.ons.gov.uk/ons/rel/ pop-estimate/population-estimates-for-uk-england-and-wales-scotlandand-northern-ireland/2013/sty-population-estimates.html.

ONS (2014b) Census 2011 -Ethnic group-Nomis at https://www.nomisweb. co.uk/census/2011/ks201ew.

Orbell S, Hagger M, Brown V, Tidy J (2006) Comparing two theories of health behavior: a prospective study of noncompletion of treatment following cervical cancer screening. Health Psychol 25: 604-615.

Peto J, Gilham C, Fletcher O, Matthews FE (2004) The cervical cancer epidemic that screening has prevented in the UK. Lancet 364: 249-256.

Quinn M, Babb P, Jones J, Allen E (1999) Effect of screening on incidence of and mortality from cancer of cervix in England: evaluation based on routinely collected statistics. BMJ 318: 904-904.

Sabates R, Feinstein L (2006) The role of education in the uptake of preventative health care: The case of cervical screening in Britain. Soc Sci Med 62: 2998-3010.

Sanders G, Craddock C, Wagstaff I (1992) Factors influencing default at a hospital colposcopy clinic. Qual Health Care 1: 236-240.

Sharp L, Cotton S, Thornton A, Gray N, Whynes D, Smart L, Waugh N, Duncan I, Cruickshank M, Little J. TOMBOLA Group (2012) Which women default from follow-up cervical cytology tests? A cohort study within the TOMBOLA trial. Cytopathology 23: 150-160.

Sharp L, Thornton A, Gray N, Cruickshank M, Whynes D, Duncan I, Hammond R, Smart L, Little J (2012) Who defaults from colposcopy? A multi-centre, population-based, prospective cohort study of predictors of non-attendance for follow-up among women with low-grade abnormal cervical cytology. Eur J Obstet Gynecol Reprod Biol 165: $318-325$.

Waller J, Jackowska M, Marlow L, Wardle J (2011) Exploring age differences in reasons for nonattendance for cervical screening: a qualitative study. BJOG 119: 26-32.

Wardle J, Pernet A, Stephens D (1995) Psychological consequences of positive results in cervical cancer screening. Psychol Health 10: 185-194.

Webb R, Richardson J, Pickles A (2004) A population-based study of primary care predictors of non-attendance for cervical screening. J Med Screen 11: $135-140$.

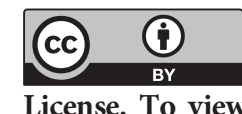

This work is licensed under the Creative Commons Attribution 4.0 International License. To view a copy of this license, visit http://creativecommons.org/licenses/by/4.0/ 